\title{
Built Environment Education. Fostering Growth in School Children
}

\author{
Educación Ambiental Construida. Fomento del Crecimiento en \\ los Estudiantes
}

\section{Educação Ambiental Construida. Promovendo o Crescimento em Crianças Escolares}

\author{
Magdalina Polinova Rajeva * \\ Children Architectural Workshop
}

\begin{abstract}
The focus of this paper is on the importance of communicating architecture to children in Bulgaria in order to increase their attitude towards the built environment and to develop their understanding of different social tendencies which affect it. The aim of this article is by investigating and analyzing different theoretical studies in the field of the Built Environment Education to create a general outline of an architectural course that can be used as a teaching method enabling creative educational growth of children in school in favour of a more just society. The paper introduces the developed methods and concepts concerning Built Environment Education in Bulgaria.
\end{abstract}

Keywords: Children, School, Architecture, Education, Environment.

El objetivo de este trabajo es comunicar la importancia de la arquitectura a los niños en Bulgaria con el fin de aumentar su actitud hacia el entorno construido y desarrollar su comprensión de las diferentes tendencias sociales que lo afectan. El objetivo de este artículo es investigar y analizar diferentes estudios teóricos en el campo de la Educación Ambiental Construida para crear un esquema general de un curso de arquitectura que pueda ser utilizado como un método de enseñanza que permita un crecimiento educativo creativo de los niños en la escuela para el desarrollo de una sociedad más justa. El documento presenta los métodos y conceptos desarrollados acerca de la Educación Ambiental Construida en Bulgaria.

Descriptores: Niños, Escuela, Arquitectura, Educación, Ambiente.

O objetivo deste trabalho é comunicar a importância da arquitetura às crianças em Bulgária com o objectivo de as sensibilizar para o ambiente construído e para o desenvolvimento de uma compreensão das suas dinâmicas sociais. O objetivo deste artigo é investigar e analisar diferentes estudos teóricos no campo da Educação Ambiental Construída para criar um curso de arquitetura que pode ser usado como método de ensino e permitir uma educação criativa na Escola e o desenvolvimento de uma sociedade mais justa. $\mathrm{O}$ documento apresenta os métodos e conceitos desenvolvidos relacionados com a Educação Ambiental Construída na Bulgária.

Palavras-chave: Crianças, Escola, Arquitetura, Educação, Ambiente.

*Contacto: m.rajeva@gmail.com

ISSN: 2254-3139

www.rinace.net/riejs/

revistas.uam.es/riejs
Recibido: $\quad 3$ de enero 2017

$1^{\text {a }}$ Evaluación: 2 de febrero 2017

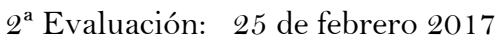

Aceptado: $\quad 3$ de marzo 2017 


\section{Introduction}

The focus of this paper is on the importance of communicating architecture to children in Bulgaria in order to increase their attitude towards the built environment and to develop their understanding of different social tendencies which affect it. By building young people`s personal relationship with the city where they live from a childhood age turns them into responsible adults in the future. Active citizenship is educated gradually. The creation of a positive attitude towards the cultural heritage and an awareness of the relationship between human activity and changes that occur in urban areas would help children to understand their role in determining the appearance of cities and the right to require quality urban environment. The aim of this article is by investigating and analysing different theoretical studies in the field of the Built Environment Education to create a general outline of an architectural course that can be used as a teaching method enabling creative educational growth of children in school in favour of a more just society. The paper introduces the developed methods and concepts concerning Built Environment Education in Bulgaria and presents two projects conducted by the organization "Children Architectural Workshop".

In the past 40 years' architects realised the importance of citizen participation in defining the spaces inhabited by them and started to work in a direction to increase public demand for an environment of better quality. In this context the children education in built environment turns to be a prior task for society. At the same time the global crisis in the field of school education creates prerequisites for the emergence of different platforms and alternative educational formats that are intended to extend the knowledge obtained by the students. In the past decades the school program in Bulgaria was focused mostly on logical and linguistic intelligence. The education system encouraging left brain activity, often neglect aesthetic, feeling, and creativity. The concept of intelligence has changed through years and in 1983 the American psychologist Howard Gardner introduced the theory of multiple intelligences in his book "Frames of Mind: The Theory of Multiple Intelligences". It is proven that social and emotional learning can help students successfully resolve conflict, communicate clearly and solve problems. Through Built Environment Education children can improve their self-confidence, empathy and social skills something that is not a prime task in the traditional education. It emphasizes on learning by doing, developing different interdisciplinary hands-on projects. It is a lifelong learning which provokes children's critical thinking and social engagement. According to Bloom`s taxonomy the top levels of classification of educational learning objectives in the cognitive domain are analysis, synthesis and evaluation. The students are expected to assess information and come to a conclusion, to present and defend opinions by making judgments. According this Built Environment Education develops student`s ability to work in a team, to observe, to notice problems and find out new creative solutions. It can support school curriculum, because is a familiar sphere that can give meaning to many abstract theories and turn them into practice. It provides a wide range of creative, cross-curricular learning opportunities for young people. With its interdisciplinary character the city is seen as a learning book that can be a source for investigating the continuity and change in the society. Nowadays it is a challenge for Bulgarian teachers to find new ways and methodologies for creating a broader education frame regarding student's individuality and emotions. 
Home, school and neighbourhood send a message to children about their place in the world. For good or ill they provide the context, the 'cadre de vie' which so affects the physical and psychological quality of their lives, and in which they start to grow into their future roles as citizens. (UIA Architecture \& Children Work Program, 2008, p. 4)

\section{Theoretical justification}

The ability to learn is one of the most outstanding human characteristics. Learning occurs continuously throughout a person's lifetime. Child's environmental education begins unconsciously with the very moment of his/her birth and is connected with the discovering of the surrounding world. Exploring his or her immediate surroundings, the child gradually expands the boundaries of his or her world developing personal skills and senses. In harmony with the natural and the built environment, the process of learning is connected with experimenting, collecting memories and upgrading our knowledge. The growth is based on an individual's way of perceiving, thinking, feeling, and doing. It is an active interaction with the built environment from which children are gathering information about space, form, colour, etc. The curiosity is the leading force which brings the child step by step towards new horizons. Until their 6th year of life children love learning by playing. They start school and suddenly all freedom and pleasure disappears. In traditional Bulgarian schools the teacher-centred model of teaching impedes student's emotional and motivational aspects of learning. Gradually children lose their inherent curiosity and the will to obtain knowledge. At the same time the school curriculum has been created by adults with no reference to child's interests or experience. Its character is more theoretical than practical and remote from nowadays society and everyday life. The child`s natural relation with the city is interrupted.

Over the years many professionals like philosophers, psychologists, architects, pedagogues and etc. became interested in the relation between young people and city where they live in order to establish new understanding of children's role in our society. The idea to include the city as part of the learning process is not new and has been known for a long time. Even in ancient Greece, Athenian pedagogues lead their students out of the physical boundaries of the school, introducing them the built environment and exploring different social interrelations and processes that happened in real life (Davis, 1960). Later on during the Enlightenment period in 18th century, in the context of changing social environment and growing citizens' participation, philosophers like John Locke and Jean-Jacques Rousseau stressed on the importance of shaping children minds early and developed the idea of relating education more with the living environment than with text books. In his book "Some thoughts concerning education" Locke criticizes the existing education curriculum and teaching, emphasizing on the importance of experience. He finds that learning has to be enjoyable and related to child's interests and inclinations. One of the most important parts of his theory about learning is related to the idea of play.

If this were minded as it should, children might be permitted to weary themselves with play, and yet have time enough to learn what is suited to the capacity of each age. But no such thing is consider'd in the ordinary way of education, nor can it well be. That rough discipline of the rod is built upon other principles, has no attraction in it, regards not what humor children are in, nor looks after favorable seasons of inclination. And indeed it would be ridiculous, when compulsion and blows have rais'd an aversion in the child to his task, to expect he should freely of his 
own accord leave his play, and with pleasure court the occasions of learning; whereas, were matters order'd right, learning anything they should be taught might be made as much a recreation to their play, as their play is to their learning. (Locke, 1884 , p. 27)

In his book "Emile, or on education" philosopher Jean-Jacques Rousseau (1762) continues Locke's ideas for education developing his thoughts about strengthening child's character and moral sense. The author examines ideas concerning relations between the individual and society and provides guidance for how to teach a boy to have a good citizenship. According to Rousseau the whole process of learning has to be in accordance with nature, giving the child an opportunity to explore and experiment. Except from nature, people can learn from other men, or from circumstances related to their personal experience and interest. The children should be taught according to their abilities enabling them to make mistakes and not protect them all the time. According to the author the education consists not in studies, in reading or writing, or in duties, but in well-chosen plays, ingenious recreations and well-directed experiments. Already in the 18th century, Rousseau developed the progressive idea of learning by doing through the surrounding environment, including material world on the one hand and human interrelations on the other -an idea which will be a starting point for the progressive movement which will rise a century later. The author believes that by strengthening both body and mind and developing all his senses the student will turn gradually in a self-confident man who doesn't know everything that goes on in the world, but knows very well what he ought to do, and how to do it. According to the author one of the fundamental principle in all good education is not to teach the child knowledge, but to give him a love for it, and a good method of acquiring it when this love has grown stronger (Rousseau, 1889).

Over a century later, in the late 19th century the progressive education movement adopted part of the ideas developed during the Enlightenment period. One of the most prominent educational reformers and follower of the idea for experiential education is the philosopher John Dewey. In his book "Experience \& Education" (Dewey, 1997a), Dewey makes comparison between traditional and progressive education, analysing the positive and negative sides of both. The imposition scheme from above and from the outside typical for the first one is opposed to the cultivation of individuality which characterise the second one. Static against dynamic and learning from abstract theories against learning through experience. According to the author "the subject - matter of traditional education consists of bodies of information and of skills that have been worked out in the past; therefore, the chief business of the school is to transmit them to the new generation" (Dewey, 1997b, p. 17). Dewey finds out that the main problem of this education is that the knowledge incorporated by adults in the textbooks doesn't correspond to the experience and abilities of the young. The abstract principles are incomprehensible and the only way to become concrete is through their application. On the other way progressive education gives the students the freedom to experience and experiment. It is more connected with the changing world and the presence rather than the remote future and past. The author emphasises on the importance of the quality of the experience and its continuity. He recommends educators to consider the cultural, social and built environment, because they are also parts of the process of interaction which can change one's personal experience. 
In 1978 Colin Ward published "The child in the city", a book that influenced the work of many professionals working in the field of Built Environment Education. It explores the relationship between children and their urban environment and examines different ways in which young people experience their surroundings. In his book Ward emphasizes on the capacity of children to adapt any environment to the purpose of playing, unconsciously learning from its architectural elements and social relations. The theme of the urban context is developed in the chapter "The city as resource" where Colin Ward writes:

The city is in itself an environmental education, and can be used to provide one, whether we are thinking of learning through the city, learning about the city, learning to use the city, to control the city or to change the city. (Ward, 1990a, p. 176)

Our urban environment can be studied in many aspects including the "hard city" of buildings, places and artefacts and the "soft city" of human contacts and activities. Ward advises teachers to use their local human resources in order to build up the autobiography of a place from the experiences of its inhabitants. In every neighbourhood there are old and retired people who will be happy to be interviewed by the children. Further on Colin Ward emphasis on the importance of children's participation in shaping their surroundings because young people "learn the art and the technique of citizenship, not through admonitions or through lectures on civics, but from involvement in real issues" (Ward, 1990b, p. 158).

In the book "Spaces for children" there is a chapter "Children's participation in planning and design: Theory, research and practice" (Hart, 2013a) written by Roger Hart. The author outlines the benefits of young people's participation in environmental planning and design, investigating its psychological aspect. Roger Hart explains the social and psychological benefits of the constructive play with materials and its significance in human development. Through building, children come across

The learning of adult roles; the opportunity to deal with emotional conflict; the discovery of physical processes and principles of spatial relationship; the ordering of the world as a means of establishing one's place in it and sense of control over it and, perhaps most important of all, the development of a sense of environmental competence. (Hart, 2013b, p. 223)

At the end of the chapter Hart concludes that the children have to be encouraged to participate in built environmental decision making because it is their democratic right and responsibility.

All of the investigated writings are related to the idea that learning through experience help children to obtain deeper and long-lasting understanding of nature of things and processes in their everyday life. The city is presented as an inexhaustible source of knowledge encouraging children`s curiosity and passion for study. By exploring and examining local built environment young people develop an awareness of space, time and change. They understand the relations between the individual and society and realize themselves as participants in different social and cultural processes. The role of play for child's natural growth appears to be an important factor for all of the researched authors. They consider that learning has to be enjoyable and related to child's interests and inclinations, criticizing the existing educational practices which are abstract and removed from everyday life. The necessity for urgent change in the school curriculum comes out as a prior task for all of the writers and the idea for implementing 
a new innovated program related to social, cultural and built environment emerged. Based on the investigated theoretical research, mentioned above, it can be concluded that generally Built environment education:

- Puts the child in the centre of the educational process

- Supplements the existing curriculum with cross-disciplinary activities

- Helps for better understanding and practical application of traditional learning

- Includes city as a teaching resource

- Connects the already existing studies with the processes which influence our built environment

- Emphasizes on learning through playing, increasing young people`s interest and curiosity through positive and healthy experiences

- Respects children`s interests and experience

- utilizes diverse materials emphasizing on recycle ones

\section{Learning Objectives}

During the last annual meeting of the World Economic Forum in Davos (January 2016) a new report "The Future of Jobs" concerning the employment, skills and workforce strategy for the future was presented. According to this study the top three skills, workers will need in 2020, would be complex problem solving, critical thinking and creativity. Nurturing further these competences will help children`s realization in the future and can serve as a starting point for developing a new interdisciplinary teaching course concerning built environment which can be implemented in school curriculum, supporting the use of a diversity of approaches to learning. It can be summarised that the main objectives of the built environment education are:

- to increase students' awareness of the spaces they live in and their understanding of the relation between people`s activities and changes in our environment both natural and built

- to understand the relation between sustainable development and future quality of life, respecting traditional building techniques and materials within a cultural context

- to give children a possibility to exercise their sensitivity, imagination, taste and critical judgment

- to develop children`s skills for observing, analysing and problem-solving

- to develop children`s skills for working in a team and communicating

- to give students an opportunity to experiment with different techniques and real materials 


\section{Methodology. Lessons from the bulgarian experience}

In Bulgarian National Primary School Curriculum architecture is introduced in art education (mainly history, composition, light, form and colour). Design education is a small part of the object "Lifestyle and technology". According to State educational requirements for curriculum content this course is designed to build the foundations of technological literacy and competence of students as an essential element of their common culture. Students rediscover the manmade world, its relations with the environment, realize the power of science and technology and participate in it. By designing, constructing, modelling and manufacturing different products and technological systems children gradually become capable to operate effectively and creatively. However, the focus is put primarily on exploration of materials and making models using work instructions. At the same time teachers are not fully confident in their knowledge of specific terminology related to architectural education, because their training usually doesn't include any courses in architecture. Another problem is the lack of funds for the purchase of various materials that are needed for the practical exercises.

The idea of introducing Built Environment Education in Bulgaria is connected with Henry Pluckrose, a primary head teacher and lead trainer of many programs in the UK. During the 1990`s he conducted several workshops with teachers and students in Bulgaria and was invited to write an article for Bulgarian magazine "Architecture". There he presented the main topics in his Built environment program and gave examples from his personal practice. According Pluckrose, by exploring the city, children gradually understand that every "architectural intervention in the landscape is a mark of history" (Pluckrose, 1997, p. 20). It had to pass over a decade for these ideas to come into practice and be perceived in Bulgaria.

In 2011 Children Architectural Workshop (see: http://archforchildren.com/) was found, a non-profit organization meant to inspire and emotionally engage children in architecture-related activities. It is the first school in Bulgaria dedicated to architecture and urbanism that's adapted especially for children and their parents. The team organizes a variety of architectural courses and after school architecture activities. They also participate in numerous cultural events in Bulgaria. In the last years the organization took part in various collaboration projects in different museums and schools working together with teachers and museum workers. For the period of their existence they worked with more than 4,000 children, developing projects like Architecture and children, Summer in the museum, Sofia through the children`s eyes, Nature, art and architecture summer school, History of architecture, Urban awareness and etc.

\subsection{Architecture and children, program in Sofia, Bulgaria}

In 2014 Children Architectural Workshop received Special mention in Institution category of Golden Cubes Awards, a competition conducted by UIA Architecture \& Children working program. The international jury evaluated Bulgarian interdisciplinary program named "Architecture and children" which explores many aspects of architecture. This informal educational course is an extra-curriculum one which is held every Saturday (three groups with 15 children each) between October and June at the Union of Architects in Bulgaria, Sofia and is adapted for children between 5 and 12 years. The tutors of the project are two architects, 12 architectural students and one 
artist whose role is to conduct and facilitate a discussion asking questions and adding information where is necessary. Supplementary materials like films, books, photos are provided in order to improve children`s understanding and to keep their interest. Every lesson starts with a short introduction of the theme concerning theory and explanation of the task. After that by participating in different hands-on activities children learn by doing individually or all together and understand the main natural principles by practice. In the last part of the lesson the students usually present their work before the others imagining fantastic stories related to the theme. Various materials like paper, cardboard, wood, clay, wire, earth, concrete, etc. are used in this course, emphasizing on recycle ones. The students in every group are usually from different schools and age which provokes new acquaintances and improve their social experience. Learning from each other is part of the process and usually the children take a leading part in definition of the problem at the beginning of each lesson. During the practical work the students are encouraged to help each other and experiment if the task allows. In all our exercises at the end we don't rate the children`s creations but encourage their individual and team work focusing on the whole process and not on the final result. As a continuation of our main course at the end of the school year in June we organize architectural workshops outdoor which aim to improve children`s competences by creating real one to one scale projects. In these exercises the students have the possibility to practice their already obtained knowledge and skills in managing with real life situations and increase their awareness towards the built environment.

\section{Main topics}

The architectural course Architecture and Children is structured on ten basic topics which allow the creation of interdisciplinary program based on various themes in the area of art and science, developing a broader minded and progressive education system ultimately related to society and everyday life. This classification was influenced by UIA Working Program Architecture \& Children Guidelines (UIA WP Architecture \& Children, 2008) and is adapted to the specific of Bulgarian cultural and social context.

Architecture and Environment: The children investigate the relationship between the natural landscape and the architectural building, by exploring their surroundings. The aim is to develop student's senses for perceiving built environment and to create initial skills for understanding simple maps and plans-read, interpret and use them for their orientation. Through city observation the students understand the relation between people`s activities and changes in our environment both natural and built. They also recognize the connection between sustainable development and future quality of life and investigate the possibilities for recycling and reuse of materials in the building of spaces to inhabit.

Architecture and Sensitivity: The students experience their environment and learn by observing with all their senses -sight, touch, hearing, smell and even taste. By exploring spaces in different ways the children improve their skills of eyes and develop visual memory, raise their awareness of sounds and recognize different sources, understand the relationship between smell and atmosphere of the place, exercise their sense of touch by examining different textures. The students notice the connection between materials, spaces and sounds and learn to connect visual images of different materials with their tactile surfaces. They also start to understand how the light and colour influence space perception and explore how architects use it in the design of their buildings. 
Architecture, Structure and Composition: The students understand the nature as a main model which inspires the creation of various architectural forms and structures. They develop a sense of scale, rhythm, shape, balance and stability of three-dimensional compositions understanding the meaning of load-bearing structures and experiencing forces of compression and tension. The children also understand the concept of scale finding out the link between human proportions and building measures.

Architecture and Function: The children develop their awareness of functional requirements of activities housed in a building. They explore the major stages in forming habitable space by examining the transition from natural shelters to the current functional environment around us. By defining basic human`s activities like housing, learning, working, relaxing, etc., the students learn to recognize different building types and understand how they reflect people`s life style and culture.

Architecture and Cultural Background: The children understand building traditions and their formation in relation to specific cultural, social, climatic, geological, and political conditions. They create a positive attitude towards Bulgarian historical heritage and monuments thinking about national and cultural identity. The study of different cities throughout the world raises students` knowledge of foreign cultures and traditions.

Architecture and History: The students examine continuity and change in the structure and form of buildings and settlements. They examine the city as a space to accumulate and rethink historical and spatial experience. The children understand the interactions between different cultures during the years and begin to recognize cultural heritage as national treasure. Students explore relationship between old and new architecture, developing critical thinking and assessment.

Architecture and Technology: The students become interested in exploration of traditional and modern building constructions and techniques. They become familiar with different building materials, developing an awareness of the importance of their energy efficient and sustainable utilization. The children understand the relation between physical characteristics of the materials and how they influence the differences in building`s form and scale.

Architecture and Design: The students become familiar with the task of an architectural concept, understanding the aim of plans, drawings and models as main architecture instruments. They recognize the members in the process of designing. The children examine the physical characteristics of space - size, shape, texture, proportion, scale, mass and colour and obtain basic skill in designing a simple plan and model.

Architecture and Other Arts: The children experience the integration of different art forms into an artistic whole that aesthetically organizes man's material and spiritual environment. They connect architecture with other visual and performing arts like sculpture, painting, music, dancing, theatre, film, etc. The students develop their sense of scale, proportion, rhythm and composition and acquire initial understanding of perspective.

Architectural Workshop Outdoors: The children participate in various outdoors activities and experiment with practical tasks creating real one to one scale models. By taking part in different city tours they learn to explore and analyse the local environment, developing their communication skills through discussions and exercise their opinion 
and critical judgment. The students become capable in the process of design and develop their technical competencies in working with different materials and instruments.

\subsection{Urban awareness project, Plovdiv, Bulgaria}

Urban Awareness is a pilot project for architectural education in school that was conducted at St. Sofronii Vrachanski High School, Plovdiv, as part of the festival One Architecture Week (see http://edno.bg/one-architecture-week-2016/festivalat). In 2016 the issue of the festival was focused on the topic of citizen participation in the creation of the urban environment. In this context the project Urban Awareness aims to stimulate young people's sensitivity and critical view at their surroundings. The program was developed and tested by the "Children architectural workshop" and aims to broaden the scope of knowledge of small citizens of the city, focusing on the role of the urban environment as a learning tool. Developing awareness and desire for active citizenship is a process that must begin in early childhood. Examining closely their city, students form a sense of belonging, social responsibility, national identity and pride. The training involved two architects, one pedagogue and 18 students from 6th grade. The project was implemented in the period March-May 2016 during the second school term, and was structured in 10 weekly exercises with duration of two hours each.

\section{Main Topics}

Our city: During the course the children investigated and analysed their district and school. They perceived the city as a living organism which was dependent on people`s activities. The students started to distinguish the different types of buildings according to their function and tried to define possible types of human activities in them. They drew a mind map, giving examples from their neighbourhood. The children examined photos of three different cities, analysing the urban environment and discussed what kind of people live there and what is their social status. At the end they played a role game in which each student has a random role (child, retirement, driver, cyclist, a mother with a small child, builder, unemployed, etc.). Depending on their role the students put their requests for changes to the mayor and the chief architect of the city (in the role are the teacher and the architect) (see figure 1).

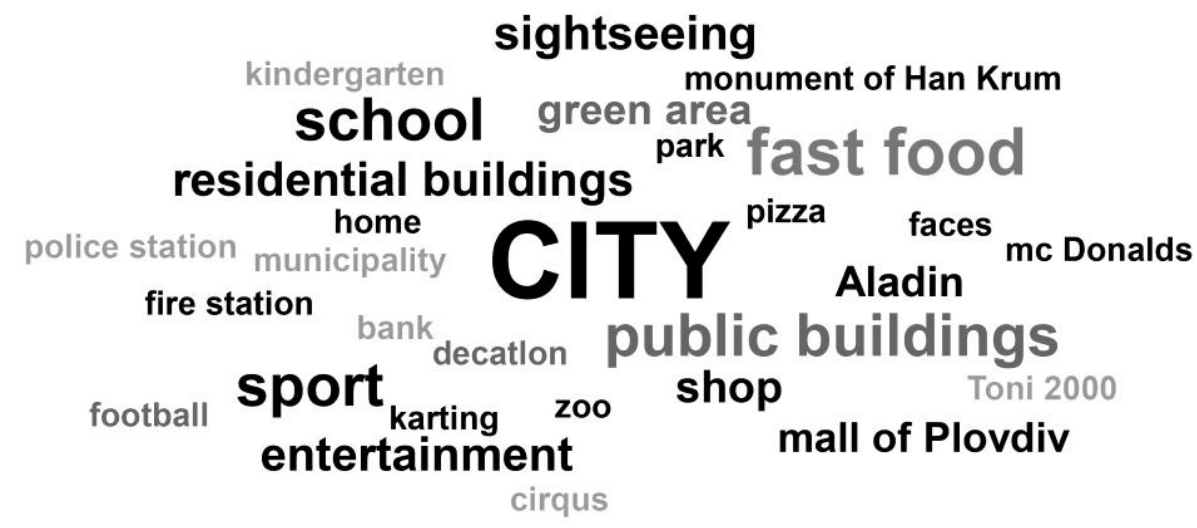

Figure 1. The students drew a mind map, giving examples from their neighbourhood Source: Elaborated by the author.

From home to school: The students investigated maps in different scales: the city, the neighbourhood, the schoolyard. They learned to use simple maps and plans by playing 
the game Treasure hunt. They started to understand the basic signs and markings and finally could find their own apartment buildings on the map. They drew their route from home to school and discussed the reasons they choose it, places of interest, meeting a friend, fastest way etc. (see figure 2).

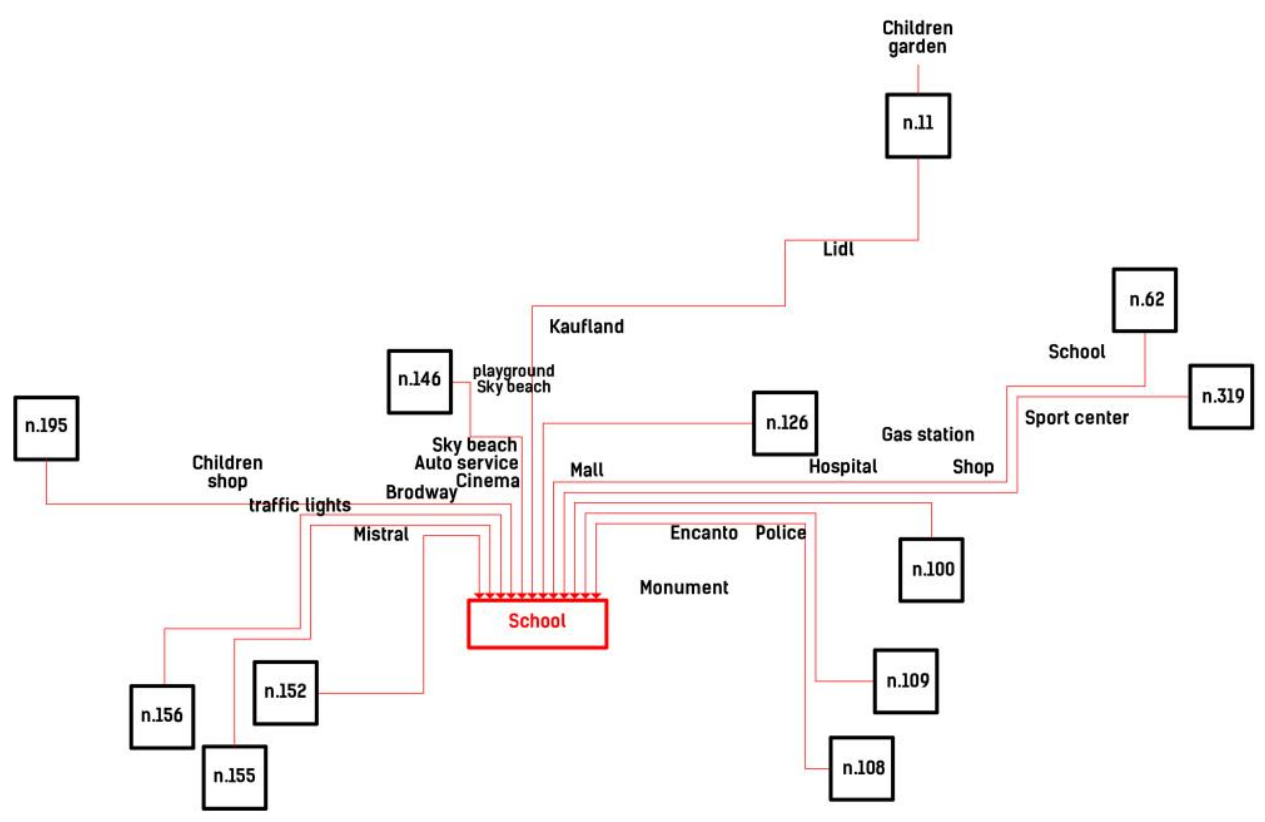

Figure 2. From home to school

Source: Elaborated by the author.

Making route: The students started to understand the building traditions and their relation with the local culture, social, geographical and political context. Students explored examples of different buildings around the world and discussed their origin and the conditions that influenced them. The children walked around the neighbourhood and identified sites they like and those they do not like. At the end they created a tourist route of all their favourite places (see figure 3).

Investigation: Students explored the surrounding built environment with all their senses: vision, touch, hearing, smell and even taste. They defined different feelings and atmosphere of the surrounding spaces. The children examined the natural light in the classroom in various hours of the day and analyse its impact on the orientation of the rooms and furnishing. They worked in groups and created maps of senses - map of noises, light/shadow map of smells and more. At the end they analysed the finished cards and defined the pleasant and unpleasant places in the school.

Dreams in school: The students examined examples of various school buildings in the world, discussing what they liked. They thought about the architectural intervention that would improve their school environment. The children made collages on black and white photos of the facades of the school and its interior space adding flowers, greenery, additional elements, street furniture and more. They were introduced with the work of the architect and get acquainted with the complete process of design and construction. They understood the purpose of different drawings and models and became acquainted with the architectural drawings of the school (plan, section, elevation), learning the main 
architectural elements. They explored different floors of the school adding lost doors, windows, columns and other missed elements on the plan (see figure 4).

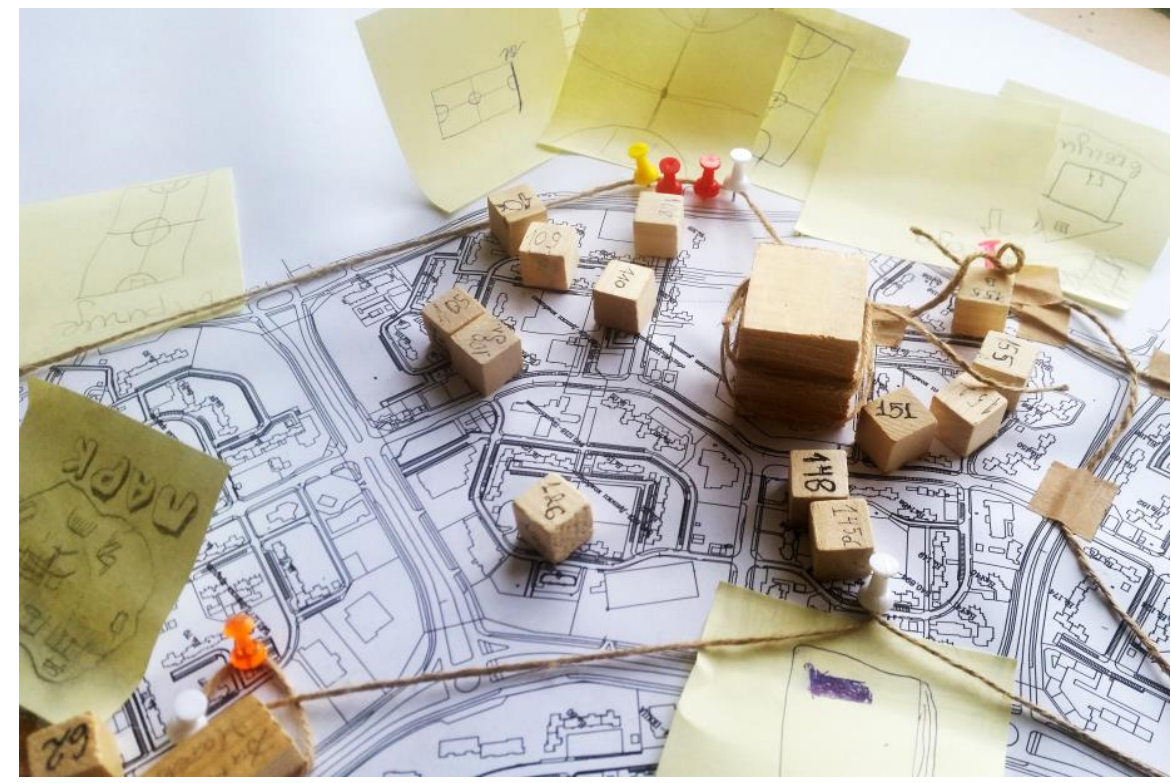

Figure 3. Model of a route of children`s favourite places in the district Source: Elaborated by Maria Dacheva.

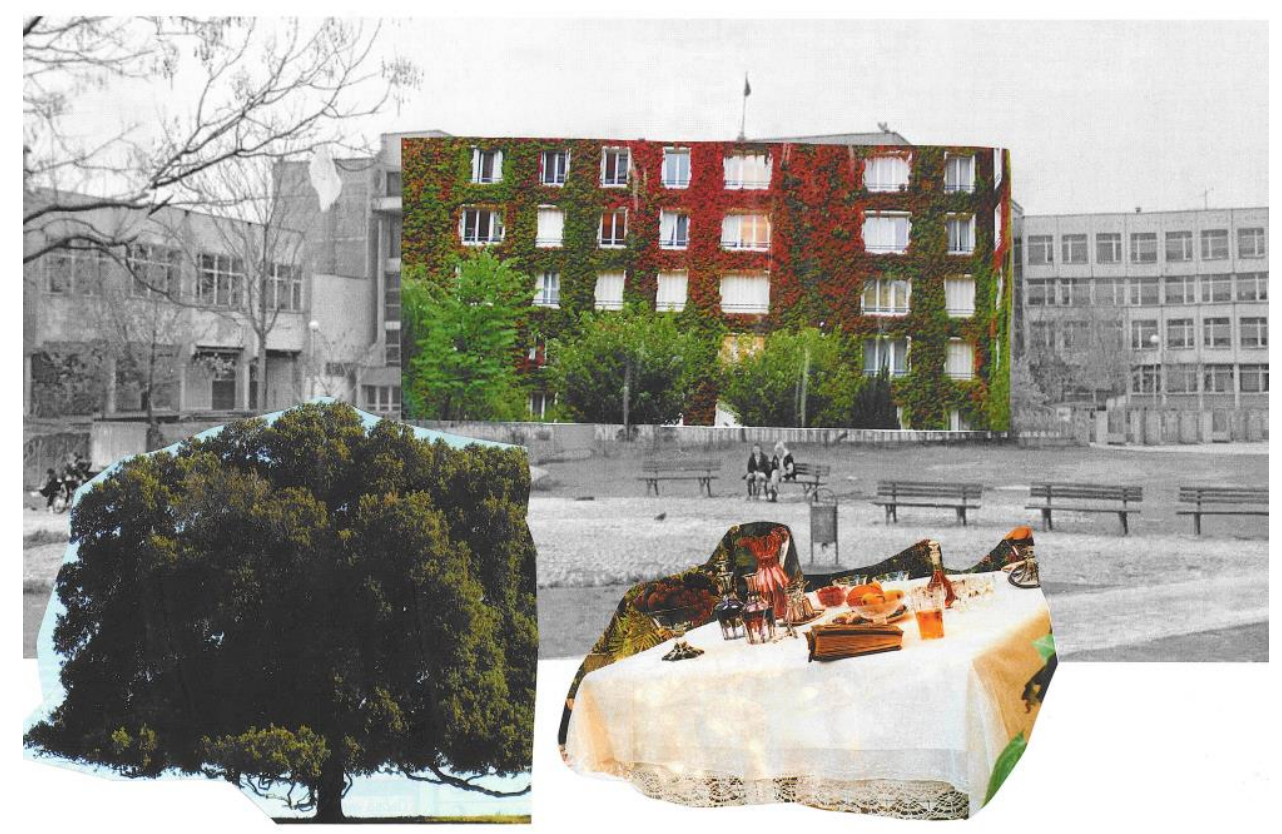

Figure 4. Collage of a dream school made by student Source: Elaborated by the author.

Making models: On the base of their observations and analysis, finally the students decided to design and create a bench in the school yard by using Euro palettes, because there were no places for sitting there. The location was chosen carefully because their bench had to be protected from sun and rain. They made a research and examined different examples of this kind of furniture. The students created a model of Euro pallet 
from cardboard in scale 1:10 and after that tried different three-dimensional structures and compositions of individual models. They thought about the relationship between human proportions and the furnishing that they used (see figure 5).

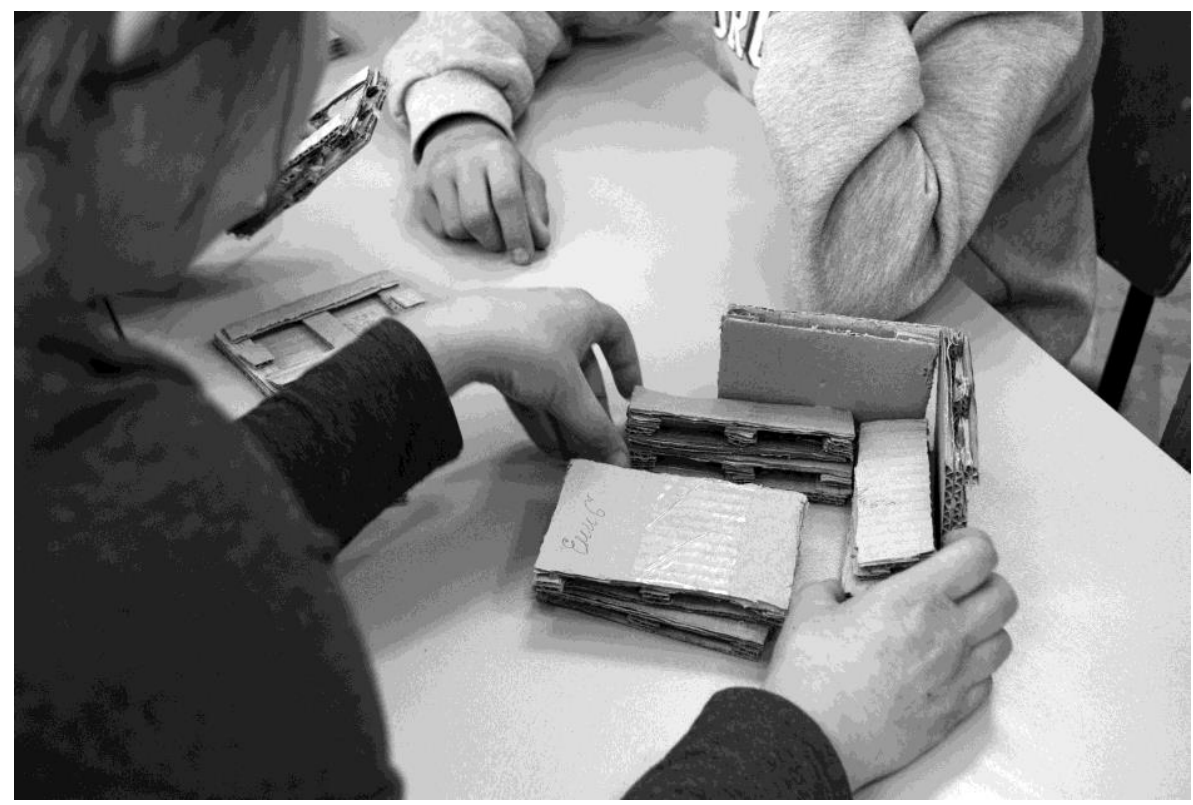

Figure 5. A model of a bench, made in 1:10 scale Source: Elaborated by Nina Toleva.

One to one scale: At the end of the project the students created one to one scale furniture and vertical garden made by recycled EUR-pallets. They developed their technical skills to work with different materials and instruments like saws, grinding machine, level, screwdriver and etc. The children could observe how this bench became a favourite stop for many other students. They were feeling responsible for the place and took care for it (see figure 6).

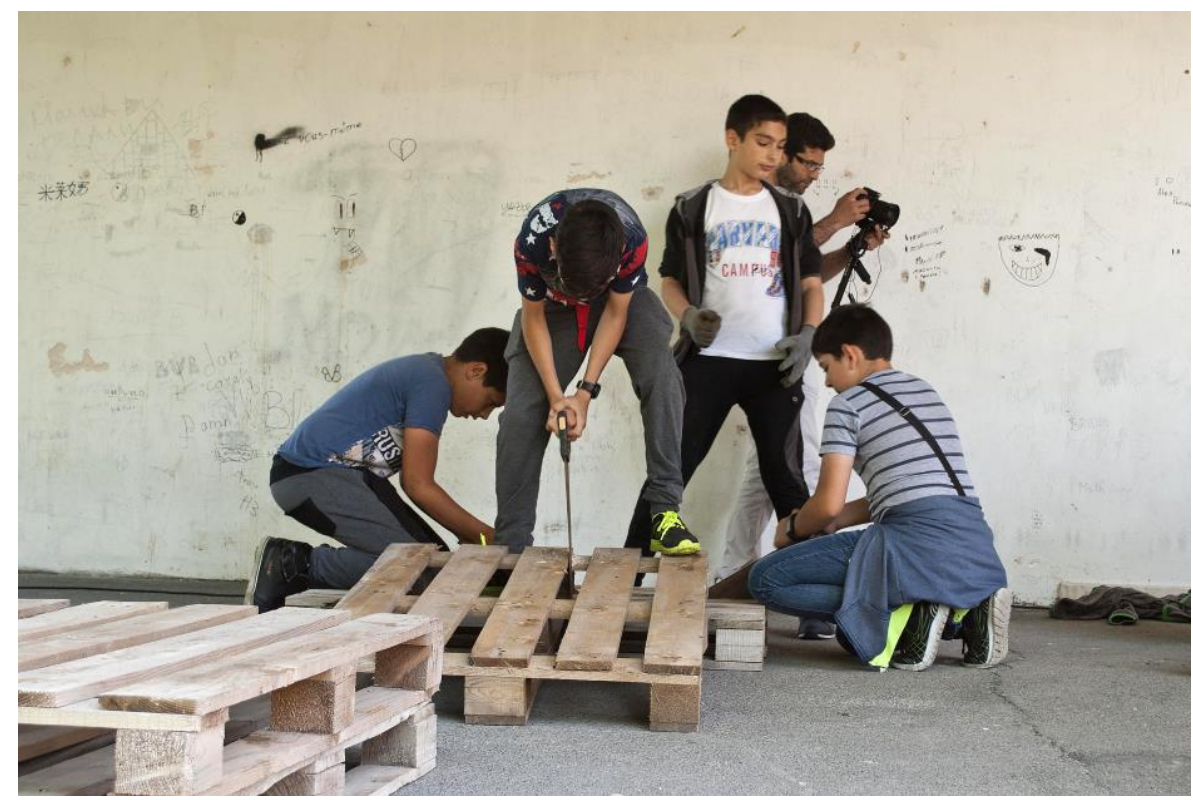

Figure 6. Students making one to one scale furniture, using EUR-pallets Source: Elaborated by Nina Toleva. 
M. Polinova Rajeva 


\section{Results}

Observing children`s development during the two courses it was noticed that their interest towards architecture was gradually increasing. It became clear that pupils were really excited experiencing their personal and familiar environment, feeling a sense of identity. They became curious about the relation between people`s activities and the changes that occur with the surrounding neighbourhood areas and understood what sustainable environment was. Students` observations started to be more precise and they developed a sense towards different details in the built environment pretending being detectives or explorers. By participating in different hands on activities children improved their fine motor skills and became acquainted with the design process, developing sense of scale, shape and stability of three-dimensional compositions. They had been learning through playing without realizing that and were really excited to find similar topics in their school programs. During the last several workshops it became clear that students increased their self-confidence and social skills. By participating in individual or team activities, even some children who were very shy at the beginning, started to be more active and enthusiastic finding new friends in the group. At the end of the school year it was observed that children became more precise and patient in their work. Gradually they increased their competences and confidence in problem solving situations and visual expressions, revealing more freely their creative potential. They also became familiar with many specific architecture terms which were introduced to them before. Some of the students were really very surprised that they enjoyed playing with recycled materials more than with plastic toys and constructors from the shop. Constructing one to one scale structures and working with real building materials created a sense of pride and significance in the young people.

It can be concluded that the architectural course includes practical exercises and activities close to the interests and competencies of students, by which they:

- Consolidate and build upon already acquired knowledge, skills and attitudes in school.

- Build cross-curricular connections.

- Apply the learned in school in their everyday life.

- Became actively involved in the improvement of their environment.

\section{Conclusions and future directions}

Nowadays the crisis of rapid urbanization needs urgent actions. During the years, adults` attention towards children gradually increases and the idea of introducing built environment to young people became a priority task for many city and country authorities. It is of a great importance that children find this kind of learning familiar and close to their former experience. They enjoy it. The investigation of different theoretical writings showed that the idea of introducing city as an educational resource is not new and could support the traditional school curriculum with a wide range of cross-discipline activities. Gradually in the year's people have developed their awareness towards the urban knowledge and understand its positive outcomes for children. The need to maximize the dissemination of this education puts its introduction in public schools where most children can benefit it regardless of their social, cultural or religious 
affiliation. The suggested architectural program is designed to supplement the existing school curriculum in Bulgaria with cross-disciplinary activities including city as a teaching resource. It has been conducted in Sofia and Plovdiv and still has to be implemented in more schools in Bulgaria. The program was evaluated by the local municipality in Plovdiv and it is going to be tested in a Roma minority neighbourhood in the city (Stolipinovo) in order to improve the relationship between the school and the neighbourhood by bringing the children back to school and providing an alternative to the static theoretical classroom activities. This is the beginning in the long process of spreading Built Environment Education in Bulgaria and can serve as basis for future investigations. Some of the following activities include the creation of a network of teachers, schools and architects, organization of teachers' training courses and developing educational printed materials. Nowadays it is important people to understand that the future quality of the environment we inhabit will be defined by our children, and their ability to make important choices will depend on the skills and knowledge they gained during their education. Because as Roger Hart writes "democratic responsibility can be acquired only through practice and involvement. It does not arise suddenly in adulthood through simple maturation; it must be fostered directly from an early age" (Hart, 2013, p. 217).

\section{References}

Davis, W. S. (1960). A day in old Athens: A picture of Athenian life. New York, NY: Biblo \& Tannen Publishers.

Dewey, J. (1997). Experience $\Xi^{2}$ Education. New York, NY: Simon \& Schuster.

Hart, R. (2013). Children`s participation in planning and design: Theory, research and practice. In C. S. Weinstein \& T. G. Davis (Eds.), Spaces for children: The built environment and child development (pp. 217-239). London: Springer Science \& Business Media.

Locke, J. (1884). Some thoughts concerning education. London: C. J. Clay, M.A. and Son, Cambridge University Press Warehouse.

Pluckrose, H. (1997). Built environment education. Architecture Magazine, 2, 1-2.

Rousseau, J. J. (1889). Emile; or, concerning education, extracts. Boston, MA: D.C. Heath \& Company.

Rousseau, J. J. (1762). Emile, or on education. Paris: Dent \& Sons

UIA Architecture \& Children Work Program. (2008). Built environment education guidelines. Retrieved from http://media.wix.com/ugd/578646_c93a3d1c37fa4ccb95b780271d7140f4.pdf

Ward, C. (1990). The child in the city. London: Bedford Square Press.

\section{Brief CV of the author}

\section{Magdalina Polinova Rajeva}

Master Degree in Architecture from the University of Architecture, Civil Engineering and Geodesy in Sofia in 2001. She runs her own architectural studio "ArchPoint" in Sofia. In 2011 she co-founded the Children Architectural Workshop, a non-profit organization, meant to inspire and emotionally engage children in architecture-derived 
activities. Thousands of students and participation in numerous cultural events has drawn the attention of the UIA Golden Cube Awards to their unique interdisciplinary approach and in 2014, the international jury awarded them with a Special mention for the project Architecture and Children. Representative of the Union of Architects in Bulgaria in the UIA working program "Architecture and Children" since 2014. ORCID ID 0000-000 1-6010-7246. Email: m.rajeva@gmail.com 